\title{
Predictive Contribution of Neutrophil/Lymphocyte Ratio in Diagnosis of Brucellosis
}

\author{
Serdar Olt, ${ }^{1}$ Hasan Ergenç, ${ }^{2}$ and Seyyid Bilal Açıkgöz ${ }^{2}$ \\ ${ }^{1}$ Department of Internal Medicine, Bitlis Mutki State Hospital, 13000 Bitlis, Turkey \\ ${ }^{2}$ Department of Internal Medicine, Sakarya University Medical Faculty Hospital, 54000 Sakarya, Turkey \\ Correspondence should be addressed to Serdar Olt; serdarolt84@yahoo.com
}

Received 13 October 2014; Revised 13 January 2015; Accepted 15 January 2015

Academic Editor: Paola Di Carlo

Copyright ( 2015 Serdar Olt et al. This is an open access article distributed under the Creative Commons Attribution License, which permits unrestricted use, distribution, and reproduction in any medium, provided the original work is properly cited.

\begin{abstract}
Here we wanted to investigate predictive value of neutrophil/lymphocyte ratio (NLR) and platelet/lymphocyte ratio (PLR) in the diagnosis of brucellosis. Thirty-two brucellosis patients diagnosed with positive serum agglutination test and thirty-two randomized healthy subjects were enrolled in this study retrospectively. Result with ROC analyzes the baseline NLR and hemoglobin values were found to be significantly associated with brucellosis $(P=0.01, P=0.01$, resp.). Herein we demonstrated for the first time that NLR values were significantly associated with brucellosis. This situation can help clinicians during diagnosis of brucellosis.
\end{abstract}

\section{Introduction}

Brucellosis is a zoonotic disease that is transmittable to humans from infected animal reservoirs especially from milk and milk products [1]. Brucellosis may present with a broad spectrum of unspecific clinical manifestations, for example, fever, chills, sweating, malaise, arthralgia, weakness, back pain, and headache [2]. Many organ systems may be involved and it can be severe like endocarditis [3]. Most commonly serum agglutination test is used for diagnosis of brucellosis and its result conforms with complement fixation or Coombs' test [4]. In the diagnosis of brucellosis the gold standard test is culture of brucellosis [5]. Which patients must we suspect for brucellosis? In our clinic we suspect feverish patients with a history of milk and milk products intake. Laboratory and clinic findings are unclear in brucellosis patients. Because brucellosis patients show unspecific symptoms and unspecific laboratory findings, we aimed to investigate predictive contribution value of neutrophil/lymphocyte ratio (NLR) and platelet/lymphocyte ratio (PLR) in diagnosis of brucellosis.

\section{Methods and Statistics}

We collected clinical and laboratory data of thirty-two patients with brucellosis diagnosed with serum agglutination test and randomized thirty-two healthy people's data from hospital records retrospectively. We collected patients' blood samples at the admission and then we analyzed laboratory parameters that consist of haematological, biochemical, and serological tests. The white blood cell (WBC) and neutrophil and lymphocyte counts were recorded and NLR and PLR were calculated from these parameters. The cut-off titer value for serum agglutination test was 1/160 in diagnosis of brucellosis. We compare haematological parameters that consist of NLR and PLR between two groups.

All analyses were performed using SPSS for Windows (version 21.0; SPSS/IBM, Chicago, IL). Student's $t$-test, Pearson's chi-squared test, and logistic regression test were used when suitable. A $P$ value $<0.05$ was considered statistically significant.

\section{Results}

The mean age of brucellosis patients was $41,7 \pm 16,1$. $62,5 \%$ of patients were male and 37,5\% female, respectively. The most common brucellosis symptoms at the time of diagnosis were fatigue $(37,5 \%)$, anorexia $(34,4 \%)$, joint pain $(34,4 \%)$, myalgia $(31,3 \%)$, fever (25\%), chills $(18,8 \%)$, and feeling cold $(18.8 \%)$, respectively (Table 1). We compare haematological parameters that consist of NLR and PLR between brucellosis patients and healthy groups. Result with ROC analyzes the baseline NLR and hemoglobin values were found to be significantly 
TABLE 1: Symptoms and signs of patients with brucellosis at the admission.

\begin{tabular}{lcc}
\hline & $n$ & $\%$ \\
\hline Fatigue & 12 & 37,5 \\
Anorexia & 11 & 34,4 \\
Joint pain & 11 & 34,4 \\
Myalgia & 10 & 31,3 \\
Sacroiliitis & 8 & 25 \\
Fever & 6 & 18,8 \\
Feeling cold & 6 & 18,8 \\
Splenomegaly & 6 & 18,8 \\
History of ingestion of fresh cheese & 5 & 15,6 \\
Chill & 4 & 12,5 \\
Hepatomegaly & 3 & 9,4 \\
Night sweats & 3 & 9,4 \\
Headache & 3 & 9,4 \\
Abdominal pain & 2 & 6,3 \\
Nausea & 1 & 3,1 \\
Vomiting & 1 & 3,1 \\
Constipation & 1 & 3,1 \\
\hline
\end{tabular}

associated with brucellosis $(P=0.01, P=0.01$, resp.) (Table 2). There were no observed significant correlations with result of Fisher's exact test for NLR and hemoglobin values (Table 3). Result with Student's t-test, the PLR, neutrophil, lymphocyte, platelet count, WBC mean values was not significantly different between two groups $(P>0.05)$ (Table 4$)$.

\section{Discussion}

We know that laboratory parameters and clinical symptoms are unspecific in brucellosis. High NLR values were found in inflammatory processes compared to noninflammatory processes in the literature [6-8].

NLR has been investigated for many diseases [9-16] but there are few studies between NLR and infectious diseases and there is not any study between brucellosis and NLR.

Therefore, we investigated predictive contribution value of NLR, PLR, and the other haematological parameters in diagnosis of brucellosis.

We compare NLR, PLR, and the other haematological parameters between brucellosis and healthy subjects. Result with ROC analyzes the baseline NLR and hemoglobin values were found to be significantly associated with brucellosis $(P=$ $0.01, P=0.01$, resp.). There were no observed significant correlations with result of Fisher's exact test for NLR and hemoglobin values $(P>0.05)$. Result with Student's $t$-test, the PLR, neutrophil, lymphocyte, platelet count, WBC mean values was not significantly different between two groups $(P>0.05)$.

In a study conducted on patients with tuberculosis and sarcoidosis, Iliaz et al. demonstrated that the NLR was higher in patients with tuberculosis compared to the patients with sarcoidosis [17].
TABLE 2: Model selection with ROC curve estimation in regression analysis for brucellosis.

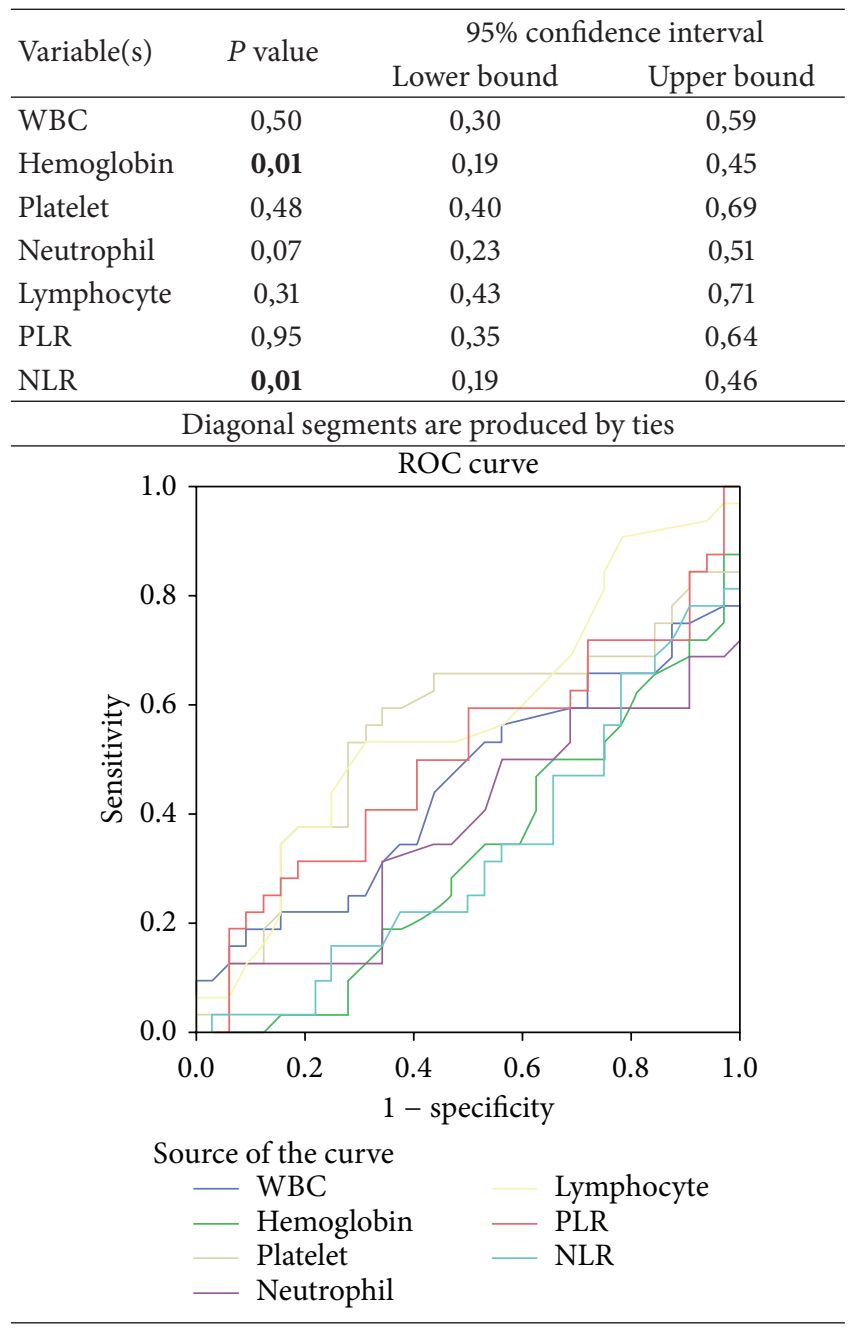

TABLE 3: Comparison of haematological parameters between brucellosis and healthy group (Fisher's exact test).

\begin{tabular}{lccc}
\hline \multicolumn{2}{c}{ Fisher's exact test } & Number & $P$ value \\
\hline \multirow{2}{*}{ NLR $<1.5$} & Healthy group & 21 & \\
& Brucellosis group & 11 & 0,06 \\
NLR $>1.5$ & Healthy group & 14 & \\
& Brucellosis group & 18 & \\
\hline \multirow{2}{*}{ Hemoglobin $<12.5$} & Healthy group & 11 & \\
& Brucellosis group & 21 & \multirow{2}{*}{0,07} \\
Hemoglobin $>12.5$ & Healthy group & 5 & \\
& Brucellosis group & 27 & \\
\hline
\end{tabular}

In a study conducted on patients with tuberculosis and bacterial community-acquired pneumonia, Yoon et al. showed that NLR levels were significantly lower in patients with pulmonary tuberculosis than in patients with bacterial community-acquired pneumonia [18].

In a study conducted on patients with Behçet disease, Rifaioglu et al. demonstrated that the NLR was higher in 
TABLE 4: Comparison of haematological parameters between brucellosis and healthy group (Student's $t$-test).

\begin{tabular}{lcccc}
\hline & & Mean & SD & $P$ value \\
\hline \multirow{2}{*}{ PLR } & Brucellosis group & 108,31 & 41,61 & \multirow{2}{*}{0,93} \\
& Healthy group & 109,29 & 46,84 & \\
\hline \multirow{2}{*}{ Neutrophil } & Healthy group & 3640,62 & 1031,08 & \multirow{2}{*}{0,10} \\
& Brucellosis group & 3106,25 & 1356,21 & \\
\hline \multirow{2}{*}{ WBC } & Brucellosis group & 6187,50 & 1968,42 & \multirow{2}{*}{0,53} \\
& Healthy group & 6459,37 & 1163,65 & \\
\multirow{2}{*}{ Platelet } & Brucellosis group & 242031,2 & 86953,63 & \multirow{2}{*}{0,67} \\
& Healthy group & 234281,2 & 62631,65 & \\
\hline \multirow{2}{*}{ Lymphocyte } & Brucellosis group & 2356,25 & 664,26 & \multirow{2}{*}{0,37} \\
& Healthy group & 2203,12 & 545,64 & \\
\hline
\end{tabular}

patients with active Behçet disease compared to controls and those with inactive Behçet disease [19].

In a study conducted on patients with Sjögren's syndrome, which is a chronic inflammatory disease, NLR was found significantly higher compared to the control group [20].

Additionally, in many studies on coronary artery disease, which is also an inflammatory process, a positive correlation was found for the NLR $[21,22]$.

In the literature high NLR values were found in inflammatory processes compared to control. In contrast with the literature data we found low NLR in brucellosis patients compared to control. In our study we demonstrated for the first time that NLR values were significantly associated with brucellosis.

Major limit of our study was the retrospective study that was considered. Single blood sampling was the other limitation of our study. For these reasons new prospectively controlled and randomized trials with multiple blood sampling must be performed to confirm our results. In spite of that we have suggested that low NLR may be useful data for brucellosis.

\section{Conflict of Interests}

The authors declare that there is no conflict of interests regarding the publication of this paper.

\section{References}

[1] E. Moreno, "Retrospective and prospective perspectives on zoonotic brucellosis," Frontiers in Microbiology, vol. 5, article 213, 2014.

[2] E. M. Galińska and J. Zagórski, "Brucellosis in humansetiology, diagnostics, clinical forms," Annals of Agricultural and Environmental Medicine, vol. 20, no. 2, pp. 233-238, 2013.

[3] M. Scarano, F. Pezzuoli, and S. Patanè, "Brucella infective endocarditis," International Journal of Cardiology, vol. 172, no. 3, pp. e509-e510, 2014.

[4] B. G. Mantur, S. K. Amarnath, and R. S. Shinde, "Review of clinical and laboratory features of human brucellosis," Indian Journal of Medical Microbiology, vol. 25, no. 3, pp. 188-202, 2007.
[5] S. Hekmatimoghaddam, M. Sadeh, M. B. Khalili, M. Mollaabedin, and A. Sazmand, "Comparison of PCR, wright agglutination test and blood culture for diagnosis of brucellosis in suspected patients," Pakistan Journal of Biological Sciences, vol. 16, no. 22, pp. 1589-1592, 2013.

[6] R. Lowsby, C. Gomes, I. Jarman et al., "Neutrophil to lymphocyte count ratio as an early indicator of blood stream infection in the emergency department," Emergency Medicine Journal, 2014.

[7] A. Yıldız, M. Yüksel, M. Oylumlu, N. Polat, M. A. Akıl, and H. Acet, "The association between the neutrophil/lymphocyte ratio and functional capacity in patients with idiopathic dilated cardiomyopathy," Anadolu Kardiyoloji Dergisi, vol. 15, no. 1, pp. 13-17, 2015.

[8] F. Imtiaz, K. Shafique, S. Mirza, Z. Ayoob, P. Vart, and S. Rao, "Neutrophil lymphocyte ratio as a measure of systemic inflammation in prevalent chronic diseases in Asian population," International Archives of Medicine, vol. 5, no. 1, article 2, 2012.

[9] A. J. Templeton, M. G. McNamara, B. Šeruga et al., "Prognostic role of neutrophil-to-lymphocyte ratio in solid tumors: a systematic review and meta-analysis," Journal of the National Cancer Institute, vol. 106, no. 6, Article ID dju124, 2014.

[10] K. Nakano, M. Hosoda, M. Yamamoto, and H. Yamashita, "Prognostic significance of pre-treatment neutrophil: lymphocyte ratio in Japanese patients with breast cancer," Anticancer Research, vol. 34, no. 7, pp. 3819-3824, 2014.

[11] L. Graziosi, E. Marino, V. de Angelis, A. Rebonato, E. Cavazzoni, and A. Donini, "Prognostic value of preoperative neutrophils to lymphocytes ratio in patients resected for gastric cancer," American Journal of Surgery, 2014.

[12] M. H. Kang, S. I. Go, H. N. Song et al., "The prognostic impact of the neutrophil-to-lymphocyte ratio in patients with smallcell lung cancer," The British Journal of Cancer, vol. 111, no. 3, pp. 452-460, 2014.

[13] Y. W. Koh, H. J. Lee, J. H. Ahn, J. W. Lee, and G. Gong, "Prognostic significance of the ratio of absolute neutrophil to lymphocyte counts for breast cancer patients with ER/PR-positivity and HER2-negativity in neoadjuvant setting," Tumor Biology, vol. 35, no. 10, pp. 9823-9830, 2014.

[14] T. Kacan, N. A. Babacan, M. Seker et al., "Could the neutrophil to lymphocyte ratio be a poor prognostic factor for non small cell lung cancers?" Asian Pacific Journal of Cancer Prevention, vol. 15, no. 5, pp. 2089-2094, 2014.

[15] J. A. Leithead, N. Rajoriya, B. K. Gunson, and J. W. Ferguson, "Neutrophil-to-lymphocyte ratio predicts mortality in patients listed for liver transplantation," Liver International, vol. 35, no. 2, pp. 502-509, 2015.

[16] M. E. Kuyumcu, Y. Yesil, Z. A. Oztürk et al., “The evaluation of neutrophil-lymphocyte ratio in Alzheimer's disease," Dementia and Geriatric Cognitive Disorders, vol. 34, no. 2, pp. 69-74, 2012.

[17] S. Iliaz, R. Iliaz, G. Ortakoylu, A. Bahadir, B. A. Bagci, and E. Caglar, "Value of neutrophil/lymphocyte ratio in the differential diagnosis of sarcoidosis and tuberculosis," Annals of Thoracic Medicine, vol. 9, no. 4, pp. 232-235, 2014.

[18] N.-B. Yoon, C. Son, and S.-J. Um, "Role of the neutrophillymphocyte count ratio in the differential diagnosis between pulmonary tuberculosis and bacterial community-acquired pneumonia," Annals of Laboratory Medicine, vol. 33, no. 2, pp. 105-110, 2013.

[19] E. N. Rifaioglu, B. B. Şen, Ö. Ekiz, and A. C. Dogramaci, "Neutrophil to lymphocyte ratio in Behçet's disease as a marker of 
disease activity," Acta Dermatovenerologica Alpina, Pannonica, et Adriatica, vol. 23, no. 4, pp. 65-67, 2014.

[20] Z. D. Hu, Y. Sun, J. Guo et al., "Red blood cell distribution width and neutrophil/lymphocyte ratio are positively correlated with disease activity in primary Sjögren's syndrome," Clinical Biochemistry, vol. 47, no. 18, pp. 287-290, 2014.

[21] S. Balta, S. Demirkol, M. Aparcı, T. Celik, and C. Ozturk, "The neutrophil lymphocyte ratio in coronary heart disease," International Journal of Cardiology, vol. 176, no. 1, p. 267, 2014.

[22] J. He, J. Li, Y. Wang, P. Hao, and Q. Hua, "Neutrophil-to- lymphocyte ratio(NLR) predicts mortality and adverse-outcomes after S T-segment elevation myocardial infarction in Chinese people," International Journal of Clinical and Experimental Pathology, vol. 7, no. 7, pp. 4045-4056, 2014. 


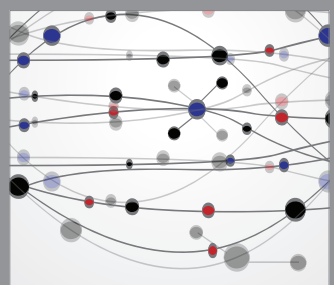

The Scientific World Journal
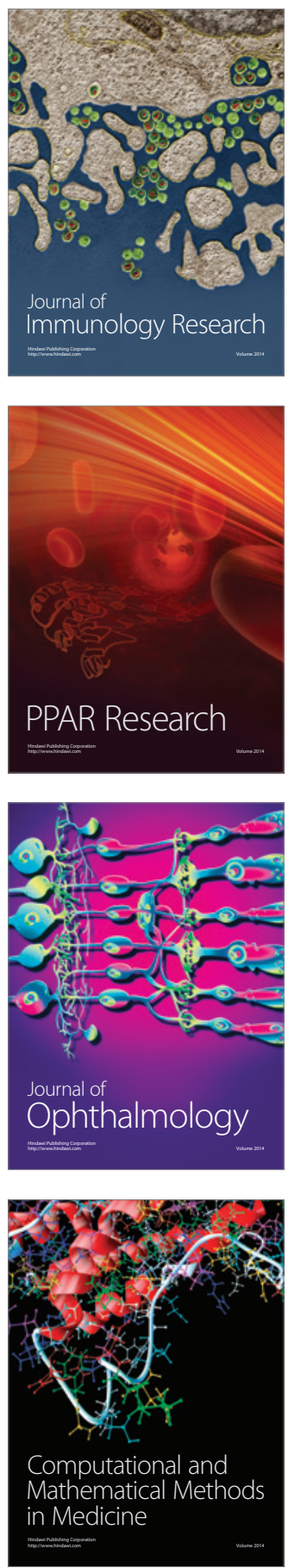

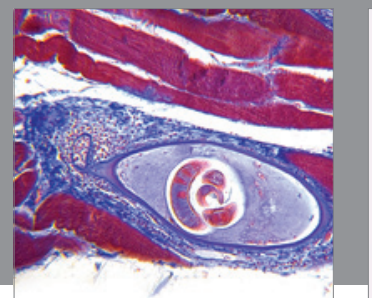

Gastroenterology

Research and Practice
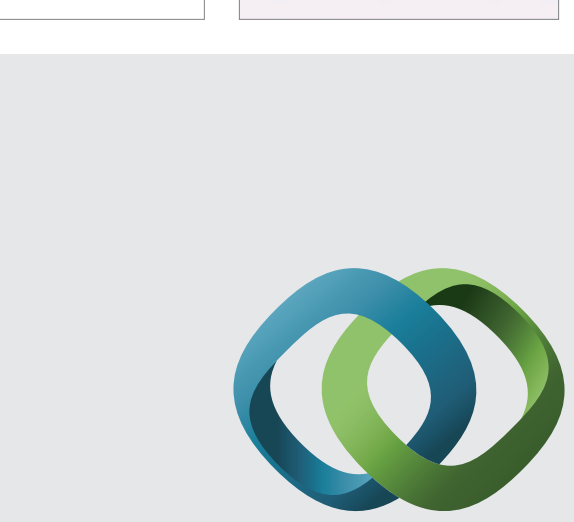

\section{Hindawi}

Submit your manuscripts at

http://www.hindawi.com
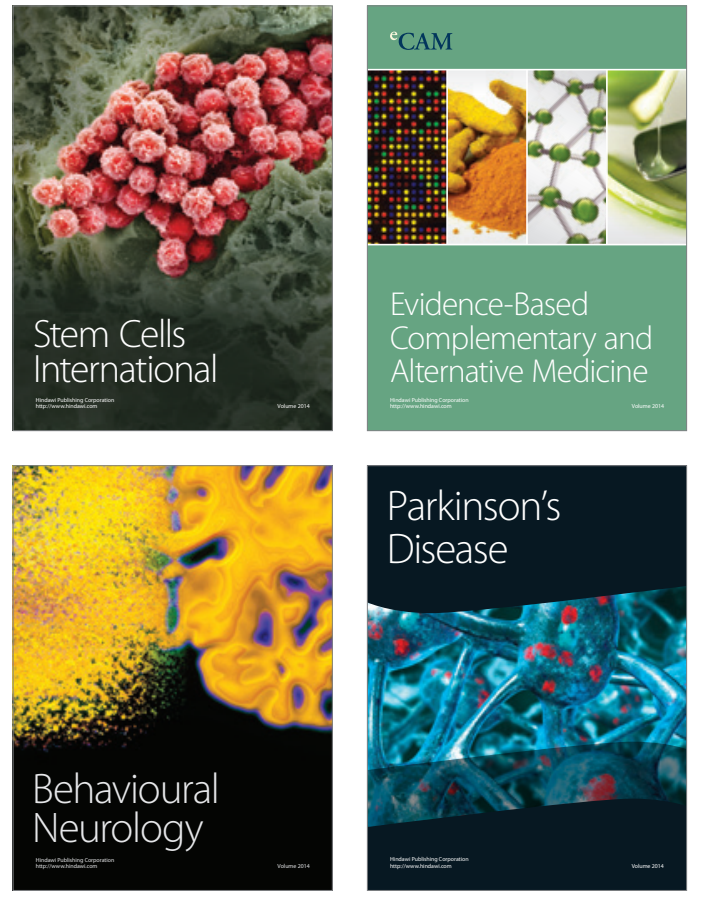
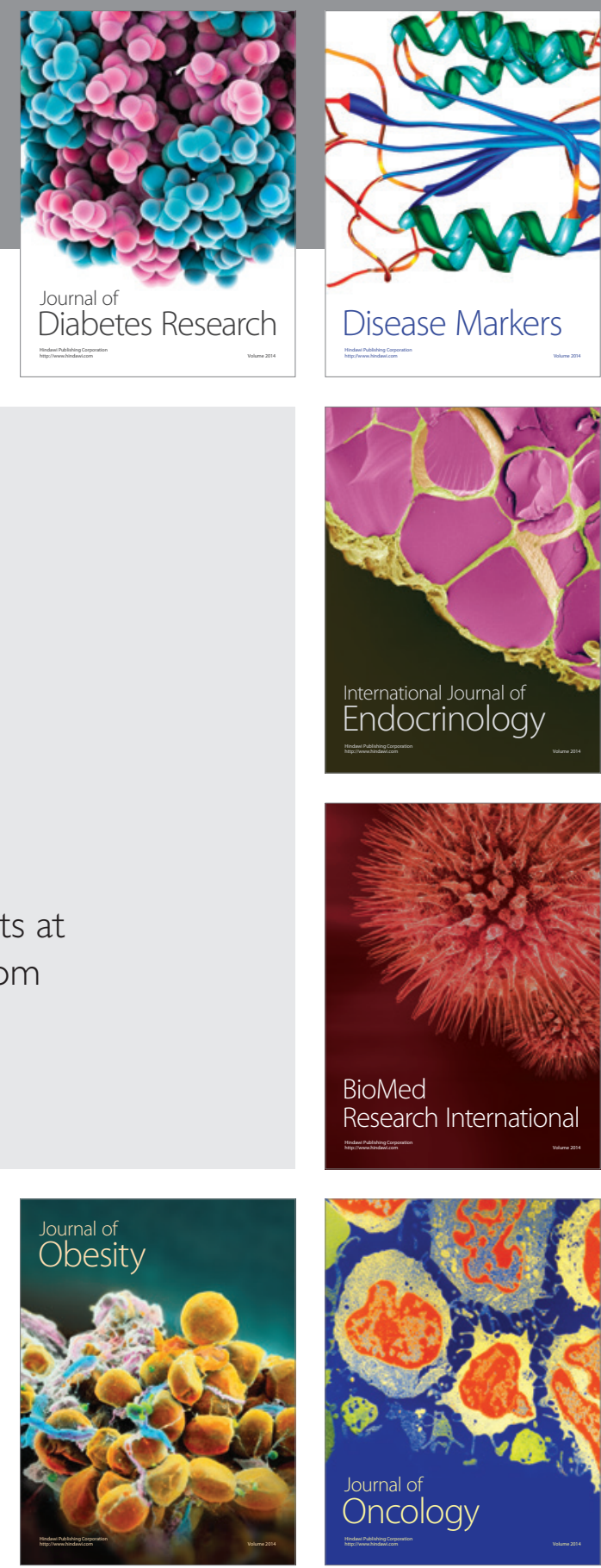

Disease Markers
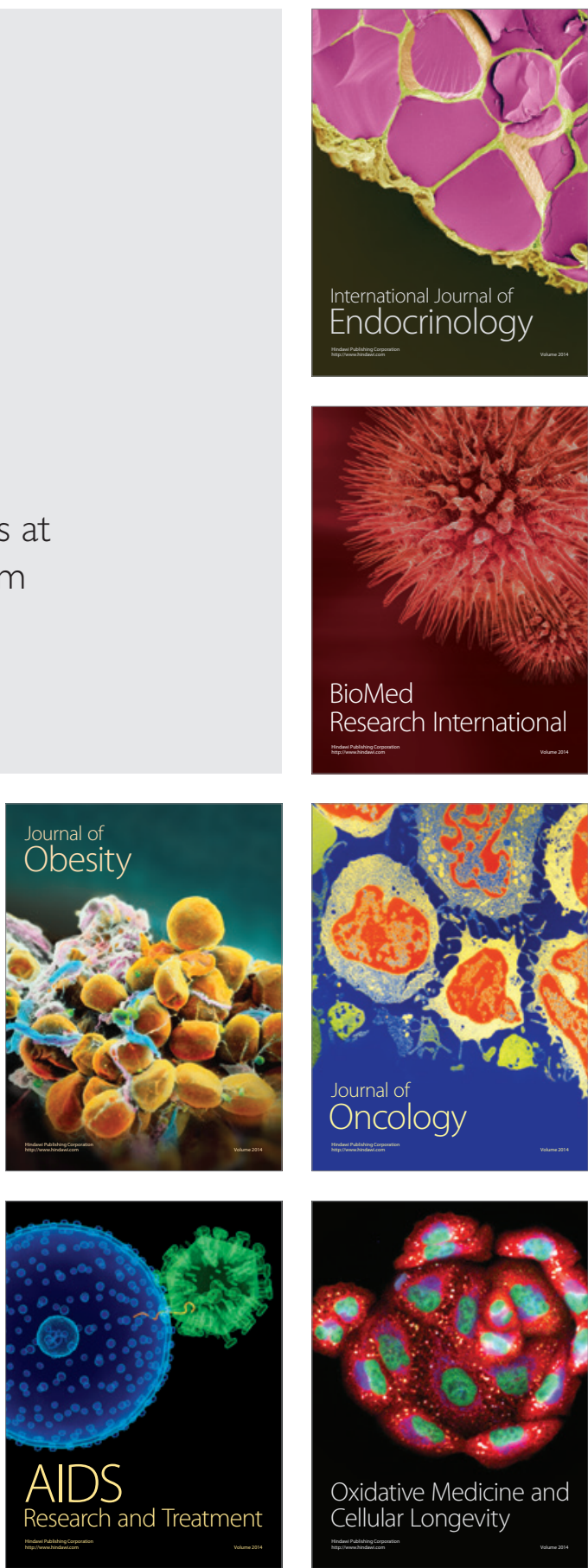